\title{
The Impact of Economy on Mergers \& Acquisitions in European Markets
}

\author{
Irina Chiriac \\ Institute of Interdisciplinary Research, Alexandru Ioan Cuza University, lasi, Romania, \\ irinaochiriac@yahoo.com
}

Received date: 3 July 2020; Accepted date:21 December 2020; Published date: 26 January 2021

Academic Editor: Marius Daraban

Copyright (C) 2021. Irina Chiriac. Distributed under Creative Commons Attribution 4.0 International CC-BY 4.0

\begin{abstract}
In this context of uncertainties and the unknown based on economic and health crises, one of the ways to save companies is the operation of merger or acquisition of companies. But not all mergers bring the expected results. The economic, political and social context can influence the evolution of the number of mergers. The aim of the paper is to analyse the impact of economy on mergers \& acquisitions, in the period 2015-2019 on European countries. The result of the analysis is that gdp, the stock index rate, the rate of opening of the economy, the reference rate of the CB (central bank) and inflation rate, are macroeconomic indicators that influence the activity of mergers and acquisitions. To reach the goals set by the analysis, we used multiple regression and SPSS.
\end{abstract}

Keywords: M\&As, economic factors, political factors, social factors

\section{Introduction}

Understanding mergers and acquisitions is very important in the current economic and health context because it is known that most mergers fail due to the limited knowledge of the managers involved in the process.

To define the concept of mergers and acquisitions strategy, we should look at the purpose of an organization. Many authors say that the foundation of a business is to obtain and maximize profit. Making a profit should not be the main goal of an organization. A costly search can hurt the company in the long run. Peter Drucker (2010) argues that the purpose of a company is to attract a customer, which in turn will lead to profit and increase, because the customer is a consumer who repeats the act of purchase.

Cite this Article as: Irina Chiriac (2021)," The Impact of Economy on Mergers \& Acquisitions in European Markets ", Journal of Financial Studies \& Research, Vol. 2021 (2021), Article ID 206635, 
In order to achieve the goal, it is necessary to draw directions of action, and these directions are provided by a strategy. Many successful businesses are experiencing a decline or stagnation in performance at some point in their history. The intensification of competition due to globalization, technological progress, high capital costs and other factors cause more and more companies to go through difficult times. The analysis of the difficulties faced by companies, as well as the means to prevent and overcome the difficult situation is very important due to the economic and social consequences of deteriorating performance or disappearance of the company. This chain reaction can disrupt an industry or the economy as a whole. Thus, mergers and acquisitions are very important.

Thus, we will analyze the relationship between the evolution of mergers and acquisitions and selected economic and social factors at the level of European countries. The analysis takes place in the period 2015-2019 on all European countries.

\section{Literature review and Hypothesis development}

In spite of the large number of studies that investigate the activities of mergers and acquisitions, most focus on microeconomic developed country markets. This study is also relevant in that it investigates the impact of global economic factors on mergers operations on a specimen of European countries with data obtained in 2015-2019.

\section{The need to analyze the connection between the evolution of mergers and acquisitions and macroeconomic factors}

Although numerous studies have had different results in relation to the influence of global economic factors on the activity of mergers and acquisitions, the topic has remained attractive due to a peculiar feature of the merger activity, namely that mergers take place in waves (Shleife, Vishny, 2003).
One of the more noticeable limitations in these studies is that the data sets are outdated, especially lacking financial information from after the financial economic crisis on $2007-2008$. Based on this gap in existing studies, I plan, in my paper, to update the dataset with more recent figures while focusing on five specific macroeconomic factors, namely gdp, the stock index rate, the rate of opening of the economy, the reference rate of the $\mathrm{CB}$ and inflation rate.

\section{Substantiation of Hypotheses}

Starting from the aim of our research, we considered the following hypotheses:

\section{Hypothesis 1 (H1).}

There exists a considerable link between the number of M\&As and GDP growth.

The authors Hyytinen and Pajarinen (2002) used to analyze the influence of the macroeconomic factors on the activity of mergers, with the following variables: the economic growth and the reference rate of the central bank. An index of high economic growth shows that in a developed economy, there are more companies and more mergers. Companies are more willing to engage in FDI deals when the economy is booming and is less willing to engage in these, deals when the economy is depressed, according to Xiaoxuan (2016). Most research focuses on how M\&A business affects firms and consumers. There is more research on how gross domestic product will trigger mergers and acquisitions. Kummer (2006) studied M\&A transactions in the South American pharmaceutical industry and found that "the number of M\&A transactions is correlated with the development and size of an economy measured in terms of GDP". Doytch and Cakan (2011) studied mergers strategies sales in different sectors and how those transactions in different sectors affect the growth of the economy. Their study showed that cross-border M\&A slows down 
the domestic economy (Doytch and Cakan, 2011). Moreover, Doytch (2012) studied the relation of M\&A supply and economic growth in OECD countries, found that mergers and acquisitions services sector $h$ a positive effect on service growth. As we can see from the literature review, even if there is some research have on the relationship between M\&A supply and economic growth, there is little research that uses the total real value of M\&A transactions in Europe in relation to gross domestic product

\section{Hypothesis 2 (H1).}

There is a direct link between the stock market index (SMI) and M\&A operations.

Merger waves appear in times of economic boom when there is a rapid growth of the economy and thus the stock index increases (Mueller, Burkhard, 1998). These can affect mergers and acquisitions for at least two reasons: first, an increased stock index helps companies finance their acquisitions. In this case, the acquiring company does not have to invest the profit or increase the debts to finance the acquisition. Another reason is related to liquidity. So, these factors increase the purchasing power of a company (Hyytinen, Pajarinen, 2002). The waves of mergers coincide with changes in the economic and technological environment. The most important force that led to the consolidation of banks in 1990 was the development of communications and data processing technology. The cost saved by using new technologies has increased with the growth of the company Broaddus, 1998). Nelson investigated the link between SMI, field of activity and number of mergers (Martynova and Renneborg 2008). By using simple regression, they established that there is a positive and important link between the variables analyzed. Nelson didnt establish a link between the field of activity of the firms involved and m\&as. Authors Clarke and Ioannidis (1996) investigated the relation between M\&a and SMI. For this they considered both the number of mergers and their value. Clarke and Ioannidis used Granger's analysis of mergers in the UK. The result of the study was that the stock market index influences both the value and the number of mergers. The same results were obtained by researchers Sharma, Mathur and Cernat-Gruci (1989). Other studies have led to different results from those mentioned above. Therefore the author Geroski (1984) did not find a significant relation between the merger activity and the macroeconomic factors. Author Guerard (1989) concludes that there is no connection between the field of activity and the activity of mergers in the United States of America.

\section{Hypothesis 3 (H1).}

\section{The CB interest rate influences the mergers activity.}

The relationship between $\mathrm{CB}$ interest rate and mergers is a widely researched subject. The researcher Marsh (1982) finds an important and negative effect on CB interest rate and the evolution of mergers and acquisitions: firms borrow less when the $\mathrm{CB}$ interest rate is high and then prefer to reorganize. In addition, Taggart (1977) also finds a significant effect of the interest rate on mergers. The bottom line is that firms are more likely to issue equity when their share prices are high and to resort to borrowing (which makes a heavily financed investment) when interest rates are low. However, unlike Marsh (1982) and Taggart (1977), the authors Choe, Masulis and Nanda (1992) find no evidence that the CB interest rate effect is significant for mergers and acquisitions.

\section{Hypothesis 4 (H1).}

\section{Between mergers and the rate of opening of the economy it is a strong link.}

The rate of opening of the economy is an indicator that reflects the degree of competitiveness of a country. The main weaknesses of the domestic economy that 
determine a low degree of competitiveness are: the precarious state of the public health system, government instability, crime, problems faced by the internal labor market (poor ethics, inadequate education, rigidity), inflation, corruption, fiscal instability, government bureaucracy and lack of infrastructure. The rate of opening of the economy is measured by the sum of exports and imports to the country's GDP. This variable is often used as a proxy to the country's trade restrictions. The size of the economy, the rate of opening of the economy and the governance level are, in most cases, positively correlated with all series of inward and outward investment.

The research hypothesis predicts that countries with higher levels of openness tend to attract more foreign investment due to reduced trading costs. A high degree of openness encourages mergers and acquisitions, according to Culem (1988), Janicki and Wunnava (2004). Some studies, namely those conducted by Aminian and Campart (2005) and Kamaly (2007), also refer to the importance of this variable in explaining international M\&A activity. Kyrkilis and Pantelis (2003) refer to the fact that the liberalization of international economic trade in a country is expected to positively influence the outflows of all kinds of investments. First, the absence of capital controls allows for unrestricted financing of investments abroad. Second, an exportoriented economy allows firms to acquire relevant information about foreign markets (knowledge, skills in organizing foreign operations and marketing their products internationally). Finally, companies can choose to combat competition from imports by involving them in the domestic markets of importing companies, and a certain form of retaliation is $M \& A$.

\section{Hypothesis 5 (H1).}

The inflation rate influences the strategy of mergers activity.
Inflation is considered one of the most important macroeconomic factors that affect investors' decision when conducting an investigation. A little existing research has done study in investigating the relationship between inflation and M\&A operations.

Authors Boateng, Hua, Uddin and Du (2014) found a negative relationship between inflation rate and the number of M\&A for UK firms during the period 1990 to 2008. The size of the coefficient shows that M\&A will decrease by $1.47 \%$ if Inflation rate increases by one unit. However, the result is not statistically significant. Furthermore, the author Black (2000) investigated the M\&A operations on American firms in mergers and acquisitions deal between 1985 and 1999. The result suggests that inflation rate is negatively related with the growth of mergers strategy.

\section{Materials and Methods}

In order to reach the objectives formulated on the thematic approach, the study is based on a research approach and methodology, which is used to obtain information meant to elucidate the questions addressed in the research.

In the research activity, the constructivist paradigm will be used by formulating hypotheses or own opinions and validating them through interpretative demonstrations, using scientific validations.

In view of the research I, resorted to establishing the following hypotheses: General hypothesis: The evolution of the number of mergers and acquisitions is influenced by factors at macroeconomic level.

The data source is the database of the Vienna Mergers and Acquisitions Institute and the European Commission database. Information collected is: number of mergers and acquisitions, the gdp, the stock index rate, the rate of opening of the economy, the reference 
rate of the $\mathrm{CB}$ (central bank) and inflation rate during 2015 - 2019.

The procedures and analysis tools used are: data collection by method of observation, statistical analysis using multiple regression procedure, SPSS 20.0 program and Pearson correlation indices.

The nature and characteristics of the variables used in the model are presented in Table 1.

\section{Table 1: The variables used in the econometric model}

\begin{tabular}{|c|c|c|}
\hline Variable & Abbreviation & Description \\
\hline \multicolumn{3}{|l|}{ Dependent variables } \\
\hline $\begin{array}{l}\text { Mergers and acquisitions } \\
\text { number rate }\end{array}$ & M\&An & $(M \& A n i, t-M \& A n i, t-1) / M \& A n i, t-1$ \\
\hline \multicolumn{3}{|l|}{ Independent variables } \\
\hline Gross domestic product rate & GDP & (GDP i,t - GDPi, t-1)/ GDP i, t-1 \\
\hline $\begin{array}{l}\text { Inflation consumer production } \\
\text { index }\end{array}$ & $\mathrm{I}$ & $(\mathrm{I} i, \mathrm{t}-\mathrm{I} \mathrm{i}, \mathrm{t}-1) / \mathrm{I} \mathrm{i}, \mathrm{t}-1$ \\
\hline Rate of opening of the economy & $\mathrm{G}$ & $\begin{array}{l}\quad \frac{\text { Import }+ \text { Export }}{G D P} \\
\mathrm{G}= \\
(\mathrm{Gi}, \mathrm{t}-\mathrm{G} \mathrm{i}, \mathrm{t}-1) / \mathrm{G} \mathrm{i}, \mathrm{t}-1\end{array}$ \\
\hline Interest rate & $\mathrm{D}$ & $(\mathrm{D} \mathrm{i}, \mathrm{t}-\mathrm{Di}, \mathrm{t}-1) / \mathrm{D} \mathrm{i}, \mathrm{t}-1$ \\
\hline Stock market index & SMI & $(\mathrm{SMI} i, \mathrm{t}-\mathrm{SMI} \mathrm{i}, \mathrm{t}-1) / \mathrm{SM} \mathrm{I} \mathrm{i}, \mathrm{t}-1$ \\
\hline
\end{tabular}

The multiple regression equation is the following:

$$
\mathrm{N}=\alpha+\beta 1 * \mathrm{GDP}+\beta 2 * \mathrm{SMI}+\beta 3 * \mathrm{G}+\beta 4 * \mathrm{D}+\beta 5^{*} \mathrm{I}+\xi
$$

\section{Results}

From table 2 it is observed that between the dependent variable - the number of mergers and the independent variable - the reference

interest - there is a strong direct link, the value of the correlation coefficient is equal to +0.849 , with a value Sig. less than 0.05 .

Table 2: Correlations

\begin{tabular}{|l|l|l|l|l|l|l|}
\hline $\mathbf{N}$ & GDP (0.0084) & SMI(0.0393) & G(0.0293) & $\mathbf{D ( 0 . 0 0 8 )}$ & $\mathbf{I}(\mathbf{0 . 0 4 6 0})$ & \\
\hline 1.000 & 0.104 & 0.584 & 0.127 & 0.849 & -0.047 & \\
\hline 0.104 & 1.000 & 0.444 & 0.023 & 0.537 & 0.435 & \\
\hline 0.584 & 0.444 & 1.000 & -0.500 & 0.621 & -0.471 & \\
\hline 0.127 & 0.023 & -0.5000 & 1.000 & 0.227 & 0.825 & \\
\hline 0.849 & 0.537 & 0.621 & 0.227 & 1.000 & 0.266 & \\
\hline-0.047 & 0.435 & -0.471 & 0.825 & 0.266 & 1.000 & \\
\hline
\end{tabular}

It is observed that $95 \%$ of the variation in the number of mergers can be explained by the accordance to table 3 . The difference is taken into account by other conjunctural factors. 
Table 3: Summary Model

\begin{tabular}{|l|l|l|l|l|}
\hline Equation & R & RSquare & $\begin{array}{l}\text { Adjusted } \\
\text { square }\end{array}$ & $\begin{array}{l}\text { Rtd. } \\
\text { error }\end{array}$ \\
\hline $\begin{array}{l}\mathbf{N}=\boldsymbol{\alpha}+\boldsymbol{\beta}^{1 *} \mathbf{G D P}+\boldsymbol{\beta}^{2} * \mathbf{S M I}+ \\
\boldsymbol{\beta}^{3 *} \mathbf{G}+\boldsymbol{\beta}^{4 *} \mathbf{D}+\boldsymbol{\beta}^{5 *} \mathbf{I}+\boldsymbol{\xi}\end{array}$ & 0.958 & 0.918 & 0.505 & 2903 \\
\hline
\end{tabular}

From table 4 it stands out the equation of the regression model, according to the resulting data, is as follows:

$$
\mathrm{N}=30222+418 * \mathrm{GDP}-1,64 * \mathrm{SMI}-0,00 * \mathrm{G}+5398 * \mathrm{D}-6611 * \mathrm{I}
$$

Thus, the regression coefficients are $\alpha=$ 30222; $\beta 1=418 ; \beta 2=-1,64 ; \beta 3=-0,00 ; \beta 5$ $=5398 ; \beta 6=-6611$.
The model reflects the influence of economic growth (GDP), the stock market index, the rate of opening of the economy, the central bank's reference interest, inflation, on the number of mergers at European level.

Table 4: Regression coefficient

\begin{tabular}{|l|l|l|l|l|l|}
\hline Variables & B & Std.error & Sig. & Tolerance & VIF \\
\hline Constant & 30222.896 & 1924.68 & - & - & - \\
\hline$G d p$ & 418.584 & 91.36 & 0.413 & 0.002 & 405.445 \\
\hline Smi & -1.640 & 14.639 & 0.084 & 0.001 & 772.599 \\
\hline$G$ & 0.000 & 0.001 & 0.393 & 0.008 & 130.630 \\
\hline$D$ & 5398.247 & 134.64 & 0.008 & 0.006 & 174.568 \\
\hline$I$ & -6611.128 & 48329 & 0.460 & 0.001 & 11.96 \\
\hline
\end{tabular}

The results provided by the model can be interpreted as follows: If we keep constant: GDP, the stock market index, the rate of opening of the economy, inflation, a percentage increase of the reference interest rate leads to an increase in the number of mergers with 5,398 transactions.

\section{Conclusions}

The merger operation is directly influenced by the lack of liquidity and the credit constraint, which occur as a result of the economic crisis.

As the Gross Domestic Product is an indicator of measuring the well-being and quality of life, we can appreciate that a high value of the Gross Domestic Product per capita reveals a good result of the activity of the national economy, being reflected in a high standard of living of population.

A decrease in the reference interest determines a general decrease in the interest rate applied by commercial banks, increases the efficiency of the use of loans for companies and guides them towards developing their activity based on the commitment of additional capital. Increasing the interest rate makes it difficult to provide the capital needed to expand the business of a company

It is known that the role of scholarships is that of financing. A company can be financed from shareholders by listing it on the stock exchange and therefore the company no 
longer needs bank loans. The stock market is a barometer of the economy, anticipates economic developments. Used for comparisons over time, it turns out that the indicator also expresses the degree to which the general state of the economy allows to obtain high profits and thus, a better remuneration of the owners. The stock market index has been declining since 2016, a year characterized by an economic crisis.

The rate of opening of the economy, is an indicator that reflects the degree of competitiveness of a country. The main weaknesses of the internal economy that determine a low degree of competitiveness are: the precarious state of the public health system, the government instability, the crime, the problems faced by the internal labor market (poor ethics, inadequate education, rigidity), inflation, corruption, fiscal instability, government bureaucracy and lack of infrastructure.

Mergers have a cyclical character. As the economy grows, this market grows oversized, and when the economy is in decline, the merger market shrinks even more. Depending on the period in which the merger operation is analyzed, the results may differ due to the specific characteristics of each merger wave.

In times of economic crisis, the number of mergers increases, a fact due to rising inflation. A euro is worth less than it was before the crisis. Thus, the purchasing power of the population decreases, so the incomes of the companies decrease, and the companies are forced to resort to the merger operation in order to survive.

The period of economic crisis and the decline of interest at global and European level did not encourage companies to merge. A decrease in the reference interest increases the efficiency of the use of loans for companies and guides them towards developing their activity based on the commitment of additional capital. The merger operation is directly influenced by the lack of liquidity and the decrease in credit, which intervene as a result of the economic crisis.

The results of this research coincide with the opinions of the authors: Nelson, Mathur, Cernat-Gruci, Clarke and Ionnadis, Broaddus, namely: there is a significant connection between the economic factors analyzed and the evolution of the number of mergers. The study is useful for knowing the context in which the merging companies operate.

\section{Acknowledgment}

This work was supported by a grant of the "Alexandru Ioan Cuza" University of Iasi, within the Research Grants program, Grant UAIC, code GI-UAIC-2018-05.

\section{References}

- Aminian, N. and Campart, S. (2005), Macroeconomic Determinants of CrossBorder Mergers and Acquisitions European and Asian Evidence, International Conference at the University of Le Havre, 2-15.

- Broaddus, A. (1998), The Bank Merger Wave: Causes and Consequences, FRB Richmond Economic Quarterly, 1-11.

- Boateng, G., Hua, X., Uddin, M., Du, M., (2014), Home country macroeconomic factors on outward cross-border mergers and acquisitions: Evidence from the UK, Research in International Business and Finance, vol. 30, issue C, 202-216.

- Cernat-Gruici, B., Hurduzeu, G., and Constantin, L.G. (2009), A century of corporate warfare- A military perspective on acquisitions and hostile takeovers, Carol I National Defence University Press, 1-19.

- Choe, H., Masulis, R.W., Nanda, V., (1993), Common stock offerings across the business cycle: Theory and evidence, Journal of Empirical finance, 3-31.

- Clarke, R. and Ioannidis, C. (1996), On the relationship between aggregate merger activity and the stock market: 
some further empirical evidence, Economics Letters, 349-356.

- Culem, G., (1988), The locational determinants of direct investments among industrialized countries, European Economic Review, vol. 32, issue 4, 885-904.

- Doytch, N., Cakan, E., Upadhyaya, K., (2011) Sectoral growth effects of Untied States mergers and acquisitions: a time series analysis, Journal of Applied Economics \& Business Research, Vol. 1, Issue 1, 4-11.

- Doytch, N., (2012) Linkages between mergers and acquisitions (M\&A) and economic growth, Business Review, Vol.1, No.3, 75-80.

- Geroski, P.A. (1984), On the relation between aggregate merger activity and the stock market, European Economic Review, 223-233.

- Guerard, J. (1989), Mergers, stock prices and industrial production, further evidence, Economics Letters, 161-164.

- Hyytinen, A. and Pajarinen, M. (2002), External finance, firm growth and the benefits of information disclosure:evidence from Finaland, ETLA Discussion Papers, Research Institute of the Finnish Economy, 1-44.

- Janicki, H., Wunnava, P., (2004), Determinants of foreign direct investment: Empirical evidence from EU accession candidates, Applied Economics, 36(5), 505-509.

- Kamaly, A. (2007), Trends and Determinants of Mergers and Acquisitions in Developing Countries in 1990s, International Research Journal of Finance and Economics, 8, 16-30.

- Kummer, C. (2006). Mergers \& acquisitions in the pharmaceutical industry in South America: activity and strategic intentions, The institute for Business and Finance Research, Vol. 1, No. 1, 169-172.

- Kyrkilis, D. and Pantelidis, P. (2003), Macroeconomic Determinants of Outward Foreign Direct Investment, International Journal of Social Economics, 30/7, 827-836.
- Martynova, M. and Renneborg, L. (2008), A century of corporate take-overs: What have we learned and where do we stand?, Journal of Banking \& Finance, 2148-2177.

- Mueller, D. and Burkhard, R. (1998), Heterogeneities within Industries and Structure-Performance Models, Working Papers 36, Oesterreichische Nationalbank, 303-320.

- Nelson, R.R. (1959), The Simple Economics of Basic Scientific Research, Journal of Political Economy, 297-306.

- Nelson, R.L. (1959), Merger movements in American industry, 1895-1956, Princeton University Press Princeton, 323.

- Sharma, S.C. and Mathur, I. (1989), Do stock market prices affect mergers?, Managerial Finance, 40-42.

- Shleifer, A. and Vishny, R.W. (2003), Stock market driven acquisitions, Journal of Financial Economics, 295-311.

- Marsh, P., (1982), The choise between equity and debt: An empirical study, The Journal of finance, 37(1), 121-144.

- Martynova, M. and Renneborg, L. (2008), A century of corporate take-overs: What have we learned and where do we stand?, Journal of Banking \& Finance, 2148-2177.

- Drucker, P., (2010), Managing people and organization, Emerald, UK, p. 93

- Taggart, R.A., (1977), A model of corporate financing decision, The Journal of Finance, 1467-1484.

- Xiaoxuan, Ji, (2016), How the GDP will affect M\&A deals in US, Southern Illinois University Carbondale, OpenSIUC, 1-23. 